\title{
A Rational Approach towards the Development of Human Carbonic Anhydrase Inhibitors as Antiepileptic Agent \\ Kalyan K Sethi ${ }^{1 *}$, Prasanta K Nayak², Hindol Sarkar ${ }^{1}$ and Saurabh M Verma ${ }^{1}$
}

${ }^{1}$ Department of Pharmaceutical Science and Technology, Birla Institute of Technology, Mesra, Ranchi, Jharkhand, India

${ }^{2}$ Department of Pharmacology, Himalayan Pharmacy Institute, Majhitar, Sikkim, India

\begin{abstract}
Antiepileptic activity study considering the MES model and molecular docking studies were performed for a series of previously synthesized dioxoisoindolin benzene sulfonamide derivatives. The reported molecules were investigated as inhibitors of the zinc metalloenzyme carbonic anhydrase (CA, EC 4.2.1.1), specifically against the hCA I and II isoforms. To get a better insight of these molecules as potential inhibitors we specifically consider the $\mathrm{hCA} \mathrm{I}$ (Ki values in the range $159 \mathrm{nM}$ to $>10000 \mathrm{nM}$ ) and hCAll (Ki values in range $1.7 \mathrm{nM}$ to $>10000 \mathrm{nM}$ ). The most potential molecule explored in the study was 3-(4,5,6,7-tetrachloro-1,3-dioxoisoindolin-2-yl)benzenesulfonamide $(\mathrm{Ki}=27.7 \mathrm{nM}), 3$-chloro-4-(4,5,6,7-tetrachloro-1,3-dioxoisoindolin-2-yl)benzenesulfonamide $(\mathrm{Ki}=4.9 \mathrm{nM})$ and 4-((4-nitro-1,3-dioxoisoindolin-2-yl)methyl)benzenesulfonamide $(\mathrm{Ki}=34 \mathrm{nM})$ respectively with obtained $\mathrm{p}$-value $<0.01$ in the MES study and showed higher antepileptic activity than acetazolamide (AZM). Moreover a well defined docking score with RMSD value of 1.8 throws light on their effective binding to the active site of both $1 \mathrm{AZM}$ and $1 \mathrm{ZFQ}$ respectively.
\end{abstract}

Keywords: Carbonic anhydrase inhibitors; Sulfonamide; Docking; Anti-epilepsy

\begin{abstract}
Abbreviations: CA: Carbonic Anhydrase; hCA: Human Carbonic Anhydrase; CAI: Carbonic Anhydrase Inhibitor; Zn: Zinc; AZM: Acetazolamide; MZA: Methazolamide; EZA: Ethoxzolamide; DCP: Dibromophenamide; DZA: Dorzolamide; BRZ: Brinzolamide; BZA: Benzolamide; TPM: Topiramate; ZNS: Zonisamide; SLP: Sulpiride; IND: Indisulam; COX: Cyclo-Oxygenase Enzyme; CLX: Celecoxib; VLX; Valdecoxib; CNS: Central Nervous System; PDB: Protein Data Bank; XP: Extra Precision; RMSD: Root Mean Square Deviation; HIS: Histidine; ASN: Asparagines; GLN: Glutamine; THR: Threonine; TRP: Tryptophan; nM: Nanomolar; mM: Milimolar.
\end{abstract}

\section{Introduction}

Carbonic anhydrases (CAs) are zinc $\left(\mathrm{Zn}^{+2}\right)$ metalloenzymes present in almost all living organism with are five genetically distinct CA families $\alpha-, \beta-, \gamma-, \delta$ - and $\zeta$-CA's [1-3]. Human CAs (hCAs) all belong to the $\alpha$-family and are present in fifteen isoforms, which differ by molecular features, oligomeric arrangement, cellular localization, distribution in organs and tissues, expression levels, and kinetic properties. CA which catalyze the interconversion between carbon dioxide and bicarbonate and involved in other physiological processes connected with respiration and transport of $\mathrm{CO}_{2}$ or bicarbonate ion, $\mathrm{CO}_{2}$ homeostasis, electrolyte secretion in many tissues, biosynthetic reactions, calcification, etc. Inhibition and activation of these enzymes are well understood processes, with most classes of inhibitors binding to the metal centre, and activators binding at the entrance of the active site cavity [1-3]

Several studies demonstrated important roles of hCAs in a variety of physiological processes, and showed that abnormal levels or activities of these enzymes have been often associated with different human diseases. ${ }^{2}$ In the last few years, several CA isozymes have become interesting targets for the design of inhibitors or activators with biomedical applications [4-7]. Indeed originally hCA inhibitors (hCAIs) were clinically used as diuretic [4], antiglaucoma [5], and antiepileptic [6-9], whereas their employment as antiobesity drugs $[10,11]$ or in the management of hypoxic tumors [12-14] were only recently validated. Well known clinically used hCAIs are Acetazolamide AAZ, Methazolamide MZA, Ethoxzolamide EZA, Dorzolamide DZA, Brinzolamide BRZ, Benzolamide BZA, Topiramate TPM, Zonisamide
ZNS, Sulpiride SLP and Indisulam IND are best known sulfonamide and its bio-isosters as antiepileptic drug (Figure 1) [1-14].

However, because of the large number of hCA isoforms, there is a constant need to improve the inhibition and selectivity profile of the so far developed CAIs, in order to avoid side effects due to inhibition of isoforms not involved in a certain pathology [1-3].

Epilepsy is a chronic neurological disorder characterized by seizures generated by the sudden, massive, synchronous excitation of neurons in the brain [6-9]. Beside the ability to block the voltage $\mathrm{Na}^{+}$-channel, to potentiate GABAergic transmission and to block the kainate/AMPA receptor, TPM occupies a particular place among new anticonvulsants due to its ability to inhibit hCA. The enzyme, catalyzing the interconversion of $\mathrm{CO}_{2}$ and $\mathrm{HCO}_{3}$ is quite abundant in the brain, being present in the glia and neurons, mainly as the cytosolic isozymes hCA II, VII and the membrane-bound isoform hCA XIV. Although their function in the brain was not well established, it is known that these proteins are involved in the secretion of cerebrospinal fluid (CSF), being present in the choroid plexus of vertebrates in high amount. Epithelial cells of the choroid plexus possess CA II, III, XII, CA VIII and CA XI (Figure 2) [8]. It also has been proven that inhibition of the brain hCAs increases the cerebral blood flow with the concomitant raising of the $\mathrm{CO}_{2}$ partial pressure. hCA inhibition might serve as an anticonvulsant mechanism (at least in some forms of epilepsy), taking into account that the contribution of $\mathrm{HCO}_{3}^{-}$current to the ionic current through $\gamma$-amino butyric acid (GABA ${ }^{3}$ receptors on dendrites is increased during periods of high-frequency receptor activation. The excitatory effect of $\mathrm{HCO}_{3}$ is blocked by membrane permeate CA inhibitors [8,9,15-17].

*Corresponding author: Kalyan K Sethi, Department of Pharmaceutical Science and Technology, Birla Institute of Technology, Mesra, Ranchi-835 215, Jharkhand, India, Tel: +918987511080; Fax: +916512275401; E-mail: kalyansethi@gmail.com

Received May 04, 2016; Accepted June 14, 2016; Published June 20, 2016

Citation: Sethi KK, Nayak PK, Sarkar H, Verma SM (2016) A Rational Approach towards the Development of Human Carbonic Anhydrase Inhibitors as Antiepileptic Agent. Med chem (Los Angeles) 6: 405-410. doi:10.4172/2161-0444.1000377

Copyright: ( 2016 Sethi KK, et al. This is an open-access article distributed under the terms of the Creative Commons Attribution License, which permits unrestricted use, distribution, and reproduction in any medium, provided the original author and source are credited. 
<smiles>CC(=O)Nc1nnc(S(N)(=O)=O)s1</smiles>

AAZ<smiles>CCNC1=C2C=C(S(N)(=O)=O)SC2S(=O)(=O)C(C)=C1</smiles><smiles>CCNC1=CN(CCCOC)S(=O)(=O)c2sc(S(N)(=O)=O)cc21</smiles>

BRZ<smiles>CCOc1ccc2nc(S(N)(=O)=O)sc2c1</smiles>

EZA<smiles>CC1(C)OC2=C(O1)C1OC(C)(C)OC1C=C2</smiles>

TPM<smiles>CCn1cccc1CNC(=O)c1cc(S(N)(=O)=O)ccc1OC(F)(F)F</smiles><smiles>NS(=O)(=O)c1ccc(S(=O)(=O)Nc2cccc3c(Cl)c[nH]c23)cc1</smiles>

IND

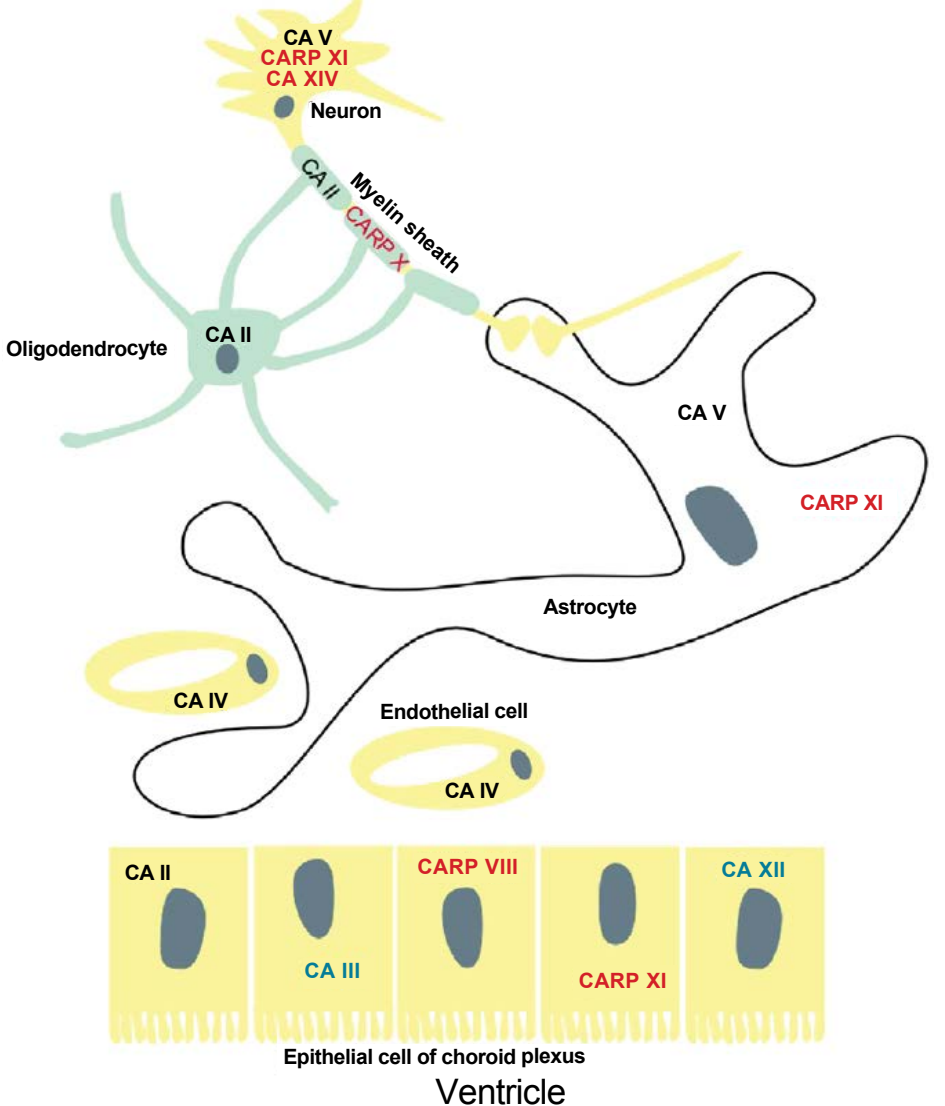

Figure 2: Schematic localization of CA isozymes in the choroid plexus within CNS. Epithelial cells of the choroid plexus possess CA II, III, XII, and CA related protein (CARP) VIII and XI. CA IV is located in endothelial cells of blood vessels. Astrocytes express both CA V and CARP XI; CARP X is present in the myelin sheath. CA II is also expressed in oligodendrocytes. Neurons contain CA V, XIV, and CARP XI. The presence of CA III and CA XII was demonstrated in the rat, whereas CARP X, $\mathrm{XI}$, and CA XIV were observed in the mouse [8]. 
Generally, the lipophilicity of compounds improve brain penetration of the drug, so that MZA or the lipophilic tert-butoxy carbonyl derivative of acetazolamide tBOC-AZA are more effective as anticonvulsants than acetazolamide, which is very hydrophilic [9].

The high lipophilicity of the best hCA inhibitors was hoped to be propitious with the crossing of the blood-brain barrier. Some of the synthesized sulfonamide derivatives by our groups [18-20] (Table 1) showed inhibitory potency against two hCA isozymes(hCA I and II) and expected to be in various important physiological processes, of the same order of magnitude as the clinically used drugs acetazolamide and methazolamide. The anticonvulsant activity of some of the best hCA inhibitors were evaluated in maximal electroshock (MES) method in mice $[1,2]$.

\section{Experimental}

\section{Anti-epileptic study}

Animals: All procedures described here were approved by the Institutional Animal Ethics Committee (Department of Pharmaceutical Sciences and Technology, Birla Institute of Technology, Mesra, Ranchi, India) and conducted in accordance with guidelines of Committee for the Purpose of Control and Supervision of Experiments on Animals (CPCSEA), Ministry of Environment and Forests, Government of India. Male albino mice (20-25 g) were obtained from Chakraborty

\begin{tabular}{|c|c|c|c|c|c|}
\hline \multirow{2}{*}{ Comp. code } & \multicolumn{2}{|c|}{$\mathrm{Ki}(\mathrm{nM})^{*}$} & \multicolumn{2}{|c|}{ Docking Score (Glide XP) } & \multirow{2}{*}{$\begin{array}{c}\text { Hydrophilic } \\
\text { Lipophilic } \\
\text { balance }\end{array}$} \\
\hline & hCA I & hCA II & 1AZM & $1 Z F Q$ & \\
\hline 1 & 432 & 68 & -5.6 & -4.7 & 1.956 \\
\hline 2 & 251 & 71 & -6.0 & -4.7 & 2.708 \\
\hline 3 & 185 & 80 & -6.1 & -4.8 & 2.378 \\
\hline 4 & 340 & 79 & -5.8 & -5.2 & 1.982 \\
\hline 5 & $>10000$ & 190 & -3.9 & -4.8 & 2.189 \\
\hline 6 & 332 & 7.1 & -5.8 & -4.5 & 2.121 \\
\hline 7 & 427 & 5.2 & -5.3 & -4.5 & 2.373 \\
\hline 8 & 326 & 2.9 & -6.1 & -4.6 & 2.455 \\
\hline 9 & 444 & 27.7 & -5.9 & -5.1 & 2.193 \\
\hline 10 & $>10000$ & 4515 & -4.1 & -3.8 & 2.955 \\
\hline 11 & 368 & 3.4 & -5.9 & -4.7 & 2.622 \\
\hline 12 & 159 & 4.9 & -5.8 & -4.6 & 2.220 \\
\hline 13 & 281 & 2.4 & -6.1 & -4.6 & 2.423 \\
\hline 14 & 318 & 4.3 & -5.6 & -5.1 & 2.597 \\
\hline 15 & 403 & 238 & -5.9 & -4.6 & 2.683 \\
\hline 16 & 295 & 589 & -6.0 & -5.5 & 2.194 \\
\hline 17 & 501 & 887 & -5.7 & -4.7 & -0.403 \\
\hline 18 & $>10000$ & $>10000$ & -3.7 & -3.8 & 0.333 \\
\hline 19 & 490 & 34 & -5.8 & -5.1 & 0.014 \\
\hline 20 & 522 & 3.9 & -5.9 & -5.1 & -0.363 \\
\hline 21 & $>10000$ & 1.7 & -3.8 & -4.7 & -0.038 \\
\hline 22 & 9600 & 35 & -5.9 & -5.1 & -0.403 \\
\hline 23 & 620 & 25 & -5.9 & -4.7 & 0.152 \\
\hline 24 & 380 & 11 & -6.1 & -5.7 & -0.227 \\
\hline 25 & 11600 & 162 & -5.9 & -5.2 & 0.064 \\
\hline 26 & 8500 & 79 & -4.4 & -5.6 & 2.475 \\
\hline AAZ & 250 & 12 & -4.8 & -3.8 & 0.455 \\
\hline
\end{tabular}

"Mean from three different assays, errors were in the range of $5-10 \%$ of the reported values [18-20] (data not shown).

Table 1: hCA I and II inhibition data with sulfonamides 1-26, standard AZM and other important CAls, by a stopped-flow $\mathrm{CO}_{2}$ hydrase assay method, docking score and hydrophilic/lipophilic balance.
Enterprises, Kolkata, India and acclimatized in the Institute's Animal House for one week. Animal house had 12:12 hr light and dark cycle (temperature $22 \pm 2^{\circ} \mathrm{C}$, relative humidity of 30 to $70 \%$ ) and mice had free access to standard rodent food and tap water.

MES-induced seizures: The maximal electroshock (MES) is a useful tool for assessing generalized tonic-clonic (grand mal) seizures [21]. Corneal stimulation produces a preferential activation of the forebrain structures, while stimulation through ear-clip electrodes activates the brain stem. In mice, MES-induced seizures consist of initial tonic flexion, then hind limb tonic extension (HLTE), followed by the stage of clonus and terminal stupor [22].

On the day of experimentation animals were randomized into groups of 5 mice each in separate labeled cages for control $(0.1 \%$ Tween $80)$, test compounds $(100 \mathrm{mg} / \mathrm{kg}$ ) and standard drugs (AZM and phenytoin; $25 \mathrm{mg} / \mathrm{kg}$ ). After $30 \mathrm{~min}$ of intraperitoneal vehicle or drug administration $(10 \mathrm{ml} / \mathrm{kg})$, maximal electroshock was delivered to all animals by a rodent electroconvulsiometer through ear clip electrodes. Seizure was induced by passing alternating current of $45 \mathrm{~mA}$ for 0.2 sduration. Animals were observed closely for $2 \mathrm{~min}$ for duration and end of HLTE which was the measure of seizure prevention efficacy. The number of animal did not show HLTE and died in a particular group within $24 \mathrm{~h}$ was used to calculate percentage protection and percentage mortality, respectively [22].

Statistical analysis: Results were expressed as mean values \pm SEM. One-way analysis of variance (ANOVA) was used for statistical comparison followed by post-hoc Newman-Keuls Multiple Comparison test and $\mathrm{P}<0.05$ was considered to be significant difference.

\section{Docking studies}

Molecular docking studies were performed in Maestro Glide v 8.5.111 (of Schrödinger) installed in a single machine running with Red Hat Linux Enterprise version 5.0 as the operating system. The ligands were built and adjusted by means of Maestro 8.5.111.

Best pose of each ligand was ranked according to the E-model energy. The docking score from Glide (Glide Score) is entirely based on Chem Score (Equation 15). It also includes a steric-clash term, adds polar terms featured by Schrodinger to correct electrostatic mismatches [23-26].

GScore $=0.065 \times$ van der Waals energy $+0.130 \times$ Coulomb energy+Lipophilic term (Hydrophobic interactions) + Hbonding + Metal binding+BuryP (Penalty for buried polar groups)+RotB (Penalty for freezing rotatable bonds)+Site (Polar interactions in the active site)

The best docked conformation is similar to the crystal structure conformation of AZM and superimposes with root mean square deviation (RMSD) of $1.5 \AA$, indicating that GLIDE is reliable software for docking of inhibitors into hCA II.

\section{Results and Discussion}

\section{hCA inhibition studies}

The hCA inhibition on cytosolic hCA I and II data of compounds 1-26 (Figure 3), the standard AZM and other clinically used sulfonamides are shown in Table 1 [2,16-19].

\section{Anti-epileptic study}

The anti-epileptic activity of the synthesized novel hCAIs was studied using mice model of MES-induced seizure at $100 \mathrm{mg} /$ $\mathrm{kg}$ intraperitoneal dose and findings are presented in Table 2. All compounds from tetrabromo-1,3-dioxoisoindolin benzenesulfonamide 
<smiles>NS(=O)(=O)c1ccc(N2C(=O)c3c(Br)c(Br)c(Br)c(Br)c3C2=O)cc1</smiles><smiles>NS(=O)(=O)c1cccc(N2C(=O)c3c(Br)c(Br)c(Br)c(Br)c3C2=O)c1</smiles><smiles>NS(=O)(=O)c1ccc(N2C(=O)c3c(Cl)c(Cl)c(Cl)c(Cl)c3C2=O)cc1</smiles><smiles>NS(=O)(=O)c1cccc(N2C(=O)c3c(Cl)c(Cl)c(Cl)c(Cl)c3C2=O)c1</smiles><smiles>NS(=O)(=O)c1ccccc1N1C(=O)c2c(Cl)c(Cl)c(Cl)c(Cl)c2C1=O</smiles><smiles>[X]c1cc(S(N)(=O)=O)ccc1N1C(=O)c2c(Cl)c(Cl)c(Cl)c(Cl)c2C1=O</smiles><smiles>NS(=O)(=O)c1ccc([Al]N2C(=O)c3ccc([N+](=O)[O-])cc3C2=O)cc1</smiles><smiles>NS(=O)(=O)c1cccc(N2C(=O)c3ccc([N+](=O)[O-])cc3C2=O)c1</smiles><smiles>NS(=O)(=O)c1ccccc1N1C(=O)c2ccc([N+](=O)[O-])cc2C1=O</smiles><smiles>NS(=O)(=O)c1ccc(CN2C(=O)c3cccc([N+](=O)[O-])c3C2=O)cc1</smiles><smiles>NS(=O)(=O)c1ccccc1N1C(=O)c2cccc([N+](=O)[O-])c2C1=O</smiles><smiles>NS(=O)(=O)c1ccc(N2C(=O)c3ccccc3C2=O)cc1S(N)(=O)=O</smiles>

Figure 3: Synthesized dioxoisoindolin benzene sulfonamide derivatives of hCAls [16-19].

series caused reduction in duration of HLTE (hind limb tonic extension), but a significant decrease was observed with compound $\mathbf{5}$ $(\mathrm{P}<0.01)$ in which two out of five animals did not show HLTE.

Three derivatives from tetrachloro-1,3-dioxoisoindolin benzenesulfonamide series, compound $7(\mathrm{P}<0.01), 9(\mathrm{P}<0.001)$ and $12(\mathrm{P}<0.01)$ demonstrated significant attenuation of HLTE with no tonic extension in up to $60 \%$ of animals. Compound $16(\mathrm{P}<0.01)$ and $18(\mathrm{P}<0.05)$ produced significant reduction in HLTE duration whereas a minor decrease was observed with other compounds in the same series. All compounds from 19-21 attenuated seizure activity in mice, but compound 19 protected $60 \%$ of animals against tonic extension and showed significant $(\mathrm{P}<0.001)$ reduction in HLTE duration. Correspondingly, all compounds from 22-26 established significantdecrease in HLTE duration while protecting up to $100 \%$ of the tested animals. Similarly, standard drugs (AZM) at $25 \mathrm{mg} /$ $\mathrm{kg}$ intraperitoneal dose significantly reduced MES-induced tonic extension while protecting 20,40 , and $80 \%$ of animals, respectively. Finally, it was evident that the protective effect produced by compound $16,24,25$, and 26 against MES-induced seizure was comparable to that of AZM (25 mg/kg, i.p.) and phenytoin ( $25 \mathrm{mg} / \mathrm{kg}$, i.p.).

\section{Docking studies}

Molecular docking of twenty six compounds and other clinically used sulfonamides were performed (Table 1) in order to find out the binding mode analysis (Figure 4). Docking was performed preferably by interest in crystal structure of hCA preferably in 1AZM (hCA I) and 1FZQ (hCA II) $[27,28]$. All the ' $A$ ' chain of the crystal structures catalytic domains of the hCA was considered for docking. The Glide (XP) score of the co-crystalliged ligand AZM is -3.8 to -4.8 and the RMSD values is 1.8 which is considered as good for docking of the ligands (Table 1). Most of the docking scores of the synthesized compounds are so good enough then standard AZM and other clinically used hCAI. Figure 


\begin{tabular}{|c|c|c|c|c|}
\hline Treatment & Dose & $\%$ Protection & $\%$ Mortality & HLTE (in Sec) \\
\hline Tween $80(0.1 \%)$ & $10 \mathrm{ml} / \mathrm{kg}$ & 0 & 40 & $17 \pm 3.24$ \\
\hline 1 & \multirow{26}{*}{$100 \mathrm{mg} / \mathrm{kg}$} & 20 & 0 & $8.4 \pm 5$ \\
\hline 2 & & 0 & 0 & $11 \pm 5.1$ \\
\hline 3 & & 0 & 20 & $13 \pm 2.2$ \\
\hline 4 & & 0 & 0 & $12 \pm 1.6$ \\
\hline 5 & & 40 & 0 & $5.4 \pm 5.4^{* *}$ \\
\hline 6 & & 0 & 20 & $14.2 \pm 0.8$ \\
\hline 7 & & $60^{\psi}$ & 0 & $5 \pm 6.9^{* *}$ \\
\hline 8 & & 0 & 0 & $11.6 \pm 1.1$ \\
\hline 9 & & $60^{\psi}$ & 0 & $4.4 \pm 6.4^{\text {tat }}$ \\
\hline 10 & & 0 & 0 & $11 \pm 1.4$ \\
\hline 11 & & 20 & 0 & $8.4 \pm 4.8$ \\
\hline 12 & & 40 & 0 & $6.4 \pm 5.9^{* *}$ \\
\hline 13 & & 20 & 0 & $9.8 \pm 5.8$ \\
\hline 14 & & 0 & 0 & $14.4 \pm 2.1$ \\
\hline 15 & & 0 & 0 & $14.4 \pm 2.7$ \\
\hline 16 & & $100^{\psi}$ & 0 & $0 \pm 0$ \\
\hline 17 & & 0 & 0 & $14.6 \pm 1.1$ \\
\hline 18 & & 40 & 0 & $7.6 \pm 7.0^{*}$ \\
\hline 19 & & $60^{\psi}$ & 0 & $3.8 \pm 5.2^{*+* *}$ \\
\hline 20 & & 0 & 0 & $11 \pm 1.6$ \\
\hline 21 & & 0 & 0 & $14.2 \pm 2.2$ \\
\hline 22 & & $60^{4}$ & 0 & $4.4 \pm 6.1^{\text {t*t* }}$ \\
\hline 23 & & 40 & 0 & $6.4 \pm 5.9^{* *}$ \\
\hline 24 & & $100^{\psi}$ & 0 & $0 \pm 0$ \\
\hline 25 & & $100^{\psi}$ & 0 & $0 \pm 0$ \\
\hline 26 & & $100^{\psi}$ & 0 & $0 \pm 0$ \\
\hline AZM & $25 \mathrm{mg} / \mathrm{kg}$ & 20 & 0 & $8.0 \pm 2.2^{*}$ \\
\hline Phenytoin & $25 \mathrm{mg} / \mathrm{kg}$ & $100^{\psi}$ & 0 & $0 \pm 0^{* * * *}$ \\
\hline
\end{tabular}

The pretreatment time before MES was $30 \mathrm{~min}$ for all drugs. Values are the mean \pm SEM for five mice. " ${ }^{* *},{ }^{* * *}$ indicates $P<0.05,0.01$, and 0.001 respectively versus control group; ANOVA followed by Newman-Keulsmultiple comparison test for HLTE and Chi-square test for percentage of protection and mortality following MES.

Table 2: Effect of novel hCAls and standard drugs against MES-induced seizure in mice.
4 has shown the docked conformations of compound 24, one of the highest docking score compound in catalytic binding pocket of hCA I and II.

The hydrophilic/lipophilic balance has been evaluated by the Schrödinger from Qikprop. QP log Po/w: Predicted octanol /water partition coefficient are with the range limit of -2.0 to 6.5 which predicts the compounds to have good cell permeability.

\section{Conclusions}

Antiepileptic activity study considering the MES model and molecular docking studies was performed for a series of previously synthesized dioxoisoindolin benzene sulfonamide derivatives and shown a better insight of these molecules as potential inhibitors we specifically consider the hCA I (Ki values in the range $159 \mathrm{nM}$ to $>10000$ $\mathrm{nM}$ ) and hCAII (Ki values in range $1.7 \mathrm{nM}$ to $>10000 \mathrm{nM}$ ). The most potential molecule explored in the study was 3-(4,5,6,7-tetrachloro-1,3dioxoisoindolin-2-yl)benzenesulfonamide $(\mathrm{Ki}=27.7 \mathrm{nM})$, 3-chloro4-(4,5,6,7-tetrachloro-1,3-dioxoisoindolin-2-yl)benzenesulfonamide $(\mathrm{Ki}=4.9 \mathrm{nM})$ and 4-((4-nitro-1,3-dioxoisoindolin-2-yl)methyl) benzenesulfonamide $(\mathrm{Ki}=34 \mathrm{nM})$ respectively with obtained $\mathrm{p}$-value $<0.01$ in the MES study and showed higher antepileptic activity than acetazolamide (AZM). Moreover, the data from anticonvulsant study showed significant protection against MES-induced seizure which further validates a relationship between hCA inhibitors and anti-epileptic activity. Some of the derivatives did not produce marked antiepileptic activity in spite of their CA inhibitor activity. This mismatch could be due to differences in pharmacokinetics as optimum blood-brain permeability is required for any drug to produce therapeutic effect in the central nervous system. The MES seizures induced by transauricular stimulation are more severe and hard to inhibit with anti-epileptic drugs as compared to MES elicited with transcorneal electrodes, due to involvement of the brain stem. However, several compounds in this study abolished all components of generalized tonic-clonic seizures suggesting higher potency that was comparable with MZA and phenytoin. Moreover a well-defined docking score with RMSD value of 1.8 throws light on their effective binding to the active site of both $1 \mathrm{AZM}$ and $1 \mathrm{ZFQ}$ respectively.
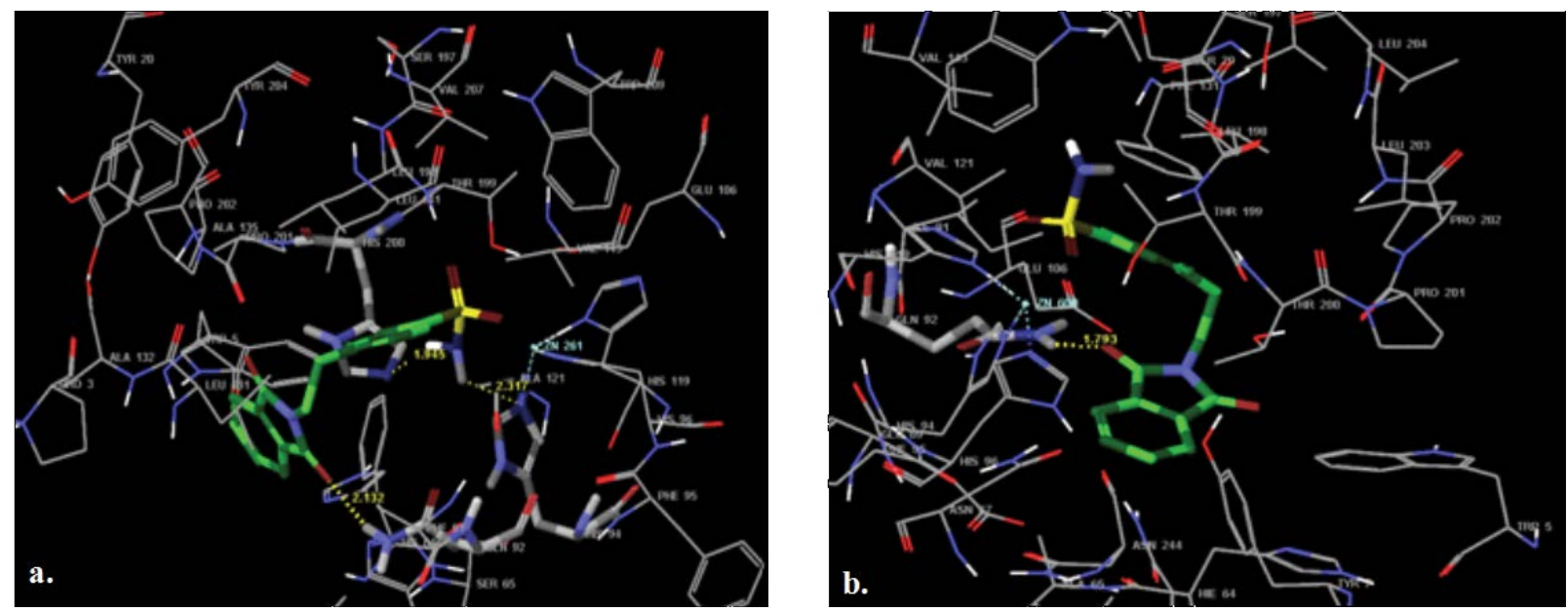

Figure 4: Docked conformations of compound 24 in the catalytic Zn binding pocket of hCA, (a) hCAI (1AZM) binding pocket formed H-bond to HIS 90 , HIS 200 , GLN 92; (b) hCA II (1ZFQ) formed hydrogen bond to GLN 92. 
Citation: Sethi KK, Nayak PK, Sarkar H, Verma SM (2016) A Rational Approach towards the Development of Human Carbonic Anhydrase Inhibitors as Antiepileptic Agent. Med chem (Los Angeles) 6: 405-410. doi:10.4172/2161-0444.1000377

\section{Acknowledgements}

This work is acknowledged to our Vice-chancellor of BIT Mesra, Ranchi who has given all the infrastructural opportunity for research. I am greatly indebted to Dr CT Supuran for the enzyme assay.

\section{References}

1. Alterio V, Di Fiore A, D'Ambrosio K, Supuran CT, De Simone G (2012) Multiple binding modes of inhibitors to carbonic anhydrases: how to design specific drugs targeting 15 different isoforms? Chem Rev 112: 4421-4468.

2. Supuran CT (2008) Carbonic anhydrases: novel therapeutic applications for inhibitors and activators. Nat Rev Drug Discov 7: 168-181.

3. Supuran CT (2008) Diuretics: From classical carbonic anhydrase inhibitors to novel applications of the sulfonamides. Curr Pharm Des 14: 641-648.

4. Supuran CT (2010) Carbonic anhydrase inhibitors. Bioorg Med Chem Lett 20: 3467-3474.

5. Kaur IP, Smitha R, Aggarwal D, Kapil M (2002) Acetazolamide: future perspective in topical glaucoma therapeutics. Int J Pharm 248: 1-14.

6. Thiry A, Dogné JM, Supuran CT, Masereel B (2007) Carbonic anhydrase inhibitors as anticonvulsant agents. Curr Top Med Chem 7: 855-864.

7. Basnyat B, Gertsch JH, Johnson EW, Castro-Marin F, Inoue Y, et al. (2003) High Alt. Efficacy of low-dose acetazolamide (125 mg BID) for the prophylaxis of acute mountain sickness: a prospective, double-blind, randomized, placebocontrolled trial. Med Biol 4: 45-52.

8. Winum JY, Thiry A, Cheikh KE, Dogné JM, Montero JL, et al (2007) Carbonic anhydrase inhibitors. Inhibition of isoforms I, II, IV, VA, VII, IX, and XIV with sulfonamides incorporating fructopyranose-thioureido tails. Bioorg Med Chem Lett 17: 2685-2691.

9. Brancaccio P, Lippi G, Maffulli N (2010) Biochemical markers of muscular damage. Clin Chem Lab Med 48: 757-767.

10. Zimmerman UJ, Wang P, Zhang X, Bogdanovich S, Forster R (2004) Antioxidative response of carbonic anhydrase III in skeletal muscle. IUBMB Life 56: 343-347.

11. Datta R, Waheed A, Bonapace G, Shah GN, Sly WS (2009) Pathogenesis of retinitis pigmentosa associated with apoptosis-inducing mutations in carbonic anhydrase IV. Proc Natl Acad Sci U S A 106: 3437-3442.

12. Tang $Y, X u$ H, Du X, Lit L, Walker W, et al. (2006) Gene expression in blood changes rapidly in neutrophils and monocytes after ischemic stroke in humans: a microarray study. Cereb Blood Flow Metab 26: 1089-1102.

13. Scozzafava A, Supuran CT, Carta F (2013) Antiobesity carbonic anhydrase inhibitors: a literature and patent review. Expert Opin Ther Pat 23: 725-735.

14. De Simone G, Di Fiore A, Supuran CT (2008) Are carbonic anhydrase inhibitors suitable for obtaining antiobesity drugs? Curr Pharm Des 14: 655-660.
15. Nishimori I, Minakuchi T, Onishi S, Vullo D, Scozzafava A, et al. (2007) Carbonic Anhydrase Inhibitors. DNA Cloning, Characterization, and Inhibition Studies of the Human Secretory Isoform VI, a New Target for Sulfonamide and Sulfamate Inhibitors. J Med Chem 50: 381-388.

16. Aspatwar A, Tolvanen ME, Ortutay C, Parkkila S (2010) Carbonic anhydrase related protein VIII and its role in neurodegeneration and cancer. Curr Pharm Des 16: 3264-3276.

17. Sethi KK, Verma SM, Prasanthi N, Annapurna MM (2011) Synthesis, Neurotoxicity and Anticonvulsant Study of Some Benzothiazole Analogs. Lett Drug Des Discov 8: 774-777.

18. Sethi KK, Verma SM, Tanç M, Carta F, Supuran CT (2013) Carbonic Anhydrase Inhibitors: Synthesis and Inhibition of the cytosolic mammalian carbonic anhydrase isoforms I, II and VII withbenzene sulfonamides incorporating 4,5,6,7-tetrachlorophthalic anhydride moiety. Bioorg Med Chem 21: 5168-5174

19. Sethi KK, Vullo D, Verma SM, Tanç M, Carta F, et al. (2013) Carbonic anhydrase inhibitors: synthesis and inhibition of the human carbonic anhydrase isoforms I, II, VII, IX and XII with benzene sulfonamides incorporating 4,5,6,7-tetrabromophthalimide moiety. Bioorg Med Chem 21: 5973-5982.

20. Sethi KK, Verma SM, Tanç M, Carta F, Supuran CT (2014) Carbonic Anhydrase Inhibitors: Synthesis and inhibition of the human carbonic anhydrase isoforms I, II, IX and XII with benzene sulfonamides incorporating 4- and 3-nitrophthalimide moieties. Bioorg Med Chem 22: 1586-1595.

21. Ilies MA, Masereel B, Rolin S, Scozzafava A, Campeanu G, et al. (2004) Carbonic anhydrase inhibitors: aromatic and heterocyclic sulfonamides incorporating adamantyl moieties with strong anticonvulsant activity. Bioorg Med Chem 12: 2717-2726.

22. Castel-Branco MM, Alves GL, Figueiredo IV, Falcão AC, Caramona MM (2009) The maximal electroshock seizure (MES) model in the preclinical assessment of potential new antiepileptic drugs. Methods Find Exp Clin Pharmacol 31: 101106.

23. Leach AR, Jhoti H (2007) Structure-based Drug Discovery. Berlin: Springer 202-207.

24. Wang R, Gao Y, Lai L (2000) LigBuilder: A Multi-Purpose Program for StructureBased Drug Design. J Mol Model 6: 498-516.

25. Schneider G, Fechner U (2005) Computer-based de novo design of drug-like molecules. Nat Rev Drug Discov 4: 649-663.

26. Jorgensen WL (2004) The many roles of computation in drug discovery. Science 303: 1813-1818.

27. Chakravarty S, Kannan KK (1994) Drug-protein interactions. Refined structures of three sulfonamide drug complexes of human carbonic anhydrase I enzyme. J Mol Biol 243: 298-309.

28. Honndorf VS, Heine A, Klebe G, Supuran CT (2006) Carbonic anhydrase II in complex with ethoxzolamidphenole as sulfonamide inhibitor. RCSB PDB. 